\title{
Observat $\mathrm{i}$ on and part $\mathrm{y}$ y char act er $\mathrm{i}$ sat $\mathrm{i}$ on of si I ver nanoparti cl es i $n$ X-ray i rradi at ed $r$ adi ophot ol um nescent phosphate gl ass
}

\begin{tabular}{|l|l|}
\hline 著者 & Zheng Wang, Kur obor i Toshi o \\
\hline $\begin{array}{l}\text { j our nal or } \\
\text { publ i cat i on t i t I e }\end{array}$ & $\begin{array}{l}\text { Nucl ear I nst rument s and Met hods i n Physi cs } \\
\text { Resear ch, Sect i on B: Beam I nt er act i ons wi th } \\
\text { Nat er i al s and At ons }\end{array}$ \\
\hline vol une & 269 \\
\hline number & 23 \\
\hline page r ange & 2814 2818 \\
\hline year & 2011- 12-01 \\
\hline URL & ht t p: //hdl . handl e. net /2297/29458 \\
\hline
\end{tabular}




\title{
Observation and partly characterisation of silver nanoparticles in X-ray irradiated radiophotoluminescent phosphate glass
}

\author{
W. Zheng, T. Kurobori* \\ Graduate School of Natural Science and Technology, Kanazawa University, Kakuma-machi, Kanazawa, \\ Ishikawa 920-1192, Japan
}

\begin{abstract}
The direct observation and characterisation of silver nanoparticles or clusters embedded in a $\mathrm{Ag}^{+}$-activated phosphate glass (PG:Ag) was demonstrated. Correlations between the isolated $\mathrm{Ag}^{+}$concentration and $\mathrm{X}$-ray-induced silver species were systematically examined using optical measurements. Evidence of spherical silver nanoparticles or clusters in X-ray-irradiated PG:Ag with sizes ranging from 5 to $30 \mathrm{~nm}$ was obtained from the lattice spacings and from energy dispersive X-ray spectroscopy (EDXS) combined with transmission electron microscopy (TEM). Three-dimensional (3D) contour plots using combined excitation-emission spectroscopy (CEES) were also recorded for X-ray-irradiated PG:Ag to allow identification of the complicated spectroscopic features of the sample.
\end{abstract}

PACS: 78.55 Hx, 78.67.Bf, 68.37.Lp, 78.70.Dm, 78.70.En

Keywords: Glass dosimeter, Nanoparticles, Radiophotoluminescence (RPL), TEM, Silver defects

*Corresponding author. fax: +81-76-234-4132.

*E-mail address: laser@kenroku.kanazawa-u.ac.jp (T. Kurobori). 


\section{Introduction}

Silver-activated phosphate glass (designated PG:Ag) based on the radiophotoluminescence (RPL) phenomenon has been widely used for personal, environmental and clinical dosimetry, as has carbon-doped aluminium oxide $\left(\mathrm{Al}_{2} \mathrm{O}_{3}: \mathrm{C}\right)$, which exhibits optically stimulated luminescence (OSL) and numerous thermoluminescence (TL) materials [1-6]. When PG:Ag is exposed to X-rays, various radiation-induced defects are produced. The existence of these defects has been confirmed by the electron spin resonance (ESR) [7, 8] and electron paramagnetic resonance (EPR) [9] methods. However, the spectral contribution of these small clusters to the overall optical spectrum of PG:Ag remains unknown.

Recently, we ascribed each X-ray-induced band of PG:Ag to silver-, phosphorus- and oxygen-related species on the basis of strong analogies with X-ray-irradiated, silver-doped sodium chloride (NaCl:Ag) [10]. Based on a peak-fitting analysis, an RPL decay curve analysis and a heat treatment, the seven decomposed Gaussian bands in X-ray-irradiated PG:Ag with peaks at 192, 225, 252, 270, 307, 354 and $424 \mathrm{~nm}$ were attributed to electron-trapped $\mathrm{PO}_{3}, \quad \mathrm{PO}_{4}$ and $\mathrm{Ag}^{+}, \quad \mathrm{Ag}_{3}{ }^{2+}$ or $\mathrm{Ag}_{3}{ }^{+}, \mathrm{Ag}_{2}{ }^{+}, \mathrm{Ag}^{2+}, \mathrm{Ag}^{0}$ and phosphorus-oxygen-hole centres (POHCs), respectively [11-13]. 
Radiation-induced $\mathrm{Ag}^{0}$ centres in glass have been extensively investigated for applications in functional optical devices because of their large, third-order nonlinear susceptibility and ultrafast nonlinear response $[14,15]$. Radiation-induced $\mathrm{Ag}^{0}$ centres have also been studied to better understand silver nanoparticles in RPL glass dosimeters for X-ray and $\gamma$-radiation applications [10-13, 16-17]. In general, silver nanoparticles in PG:Ag are typically prepared through the introduction of $\mathrm{Ag}^{+}$ions into the host, followed by irradiation with low-intensity femtosecond (fs) laser pulses and subsequent heat treatment at a high temperature for several hours $[18,19]$. These processes reduce the $\mathrm{Ag}^{+}$ions to $\mathrm{Ag}^{0}$ atoms, which results in the formation of plasmonic nanoparticles within the matrix.

Recently, Jiménez et al. [20] reported the optical properties of a silver-doped phosphate glass system of the $\mathrm{P}_{2} \mathrm{O}_{5}, \mathrm{Al}_{2} \mathrm{O}_{3}, \mathrm{CaO}$ and $\mathrm{BaO}$ type with relatively high concentrations of silver and tin (i.e., $8 \mathrm{~mol} \%$ of each $\mathrm{Ag}_{2} \mathrm{O}$ and $\mathrm{SnO}$ ) during heat treatment in the $400-500^{\circ} \mathrm{C}$ temperature range. They observed the surface plasmon resonance (SPR) of Ag nanoparticles using chemical reduction processes during heat treatment without radiation irradiation.

However, in the case of X-ray irradiation, no discernible absorption band for the silver nanoparticles due to the SPR near $407 \mathrm{~nm}$ [11] was observed in this work after heavy X-ray irradiation and further annealing at $573 \mathrm{~K}$ for $30 \mathrm{~min}$. On the contrary, for the case of high peak power and high repetition rate fs laser pulse irradiation, we demonstrated the formation kinetics of the surface plasmonic Ag nanoparticles embedded in PG:Ag using a high 
repetition rate of over $250 \mathrm{kHz}$ for the fs laser pulse irradiation [11]. Moreover, it was found that fs laser irradiation with a peak power density over $10^{15} \mathrm{~W} / \mathrm{cm}^{2}$ enabled direct precipitation in PG:Ag without heat treatment, as observed previously [21] in $\mathrm{Ag}^{+}$-doped silicate glass.

Despite these advances, the following question remains. What kinds of nanoparticles can be formed within RPL glass system of the $\mathrm{P}_{2} \mathrm{O}_{5}, \mathrm{Al}_{2} \mathrm{O}_{3}$ and $\mathrm{Na}_{2} \mathrm{O}$ type with relatively low concentration of $\mathrm{Ag}_{2} \mathrm{O}$ (only $0.17 \mathrm{wt} \%$ ) used in this work by X-ray irradiation? The aim of this study was to reveal the presence and identify the structures of the nanoparticles embedded in PG:Ag after X-ray irradiation. Direct observation was carried out by transmission electron microscopy (TEM). Correlations between the isolated $\mathrm{Ag}^{+}$concentration and X-ray-induced silver species were also examined using optical measurements as a function of X-ray dose in the range from 4.90 to $147 \mathrm{~Gy}$.

\section{Experimental details}

A commercially available GD-450 dosimeter (AGC Techno Glass) was used as the radiophotoluminescent PG:Ag. In general, the glass GD-450 dosimeter is set in a plastic holder with embedded plastic and metal filters used for radiation discrimination [3]. However, in this study, all of the measurements including X-ray irradiation were carried out in air 
without the plastic holders. Samples were cut from the original dosimeter plate to a size of approximately $10 \times 7 \times 1 \mathrm{~mm}^{3}$. For the measurement of the optical absorption spectra, samples were used about $0.30 \mathrm{~mm}$ in thickness. The weight composition of the GD-450 dosimeter was 31.55\% P, 51.16\% O, 6.12\% Al, 11.00\% Na and 0.17\% Ag. All samples were coloured by irradiation from an X-ray unit $(8.05 \mathrm{keV})$ with a copper target that was operated at $30 \mathrm{kV}$ and $20 \mathrm{~mA}$. The samples were irradiated such that the absorbed doses ranged from 4.90 to 147 Gy. Optical absorption, excitation, photoluminescence (PL), RPL spectra and three-dimensional (3D) contour plots, i.e., combined excitation-emission spectroscopy (CEES) [22, 23], of the X-ray-irradiated PG:Ag samples were determined at room temperature using Hitachi U-3900H UV-Vis and F-4500 fluorescence spectrophotometers.

Direct observation of the nanoparticles or clusters formed after X-ray irradiation by TEM was carried out with a JEOL JEM-2010FEF operating at $200 \mathrm{kV}$. The TEM 100 mesh grids used in this study were made of copper with a carbon support film that was approximately 15 nm in thickness. The X-ray-irradiated PG:Ag was thinned down with $5 \%$ hydrofluoric acid (HF) and the sample was then ground into a powder. The powder was dispersed in distilled water under ultrasonication for $15 \mathrm{~min}$ and then a $50 \mu \mathrm{l}$ nanoparticle suspension was dropped onto parafilm. The grid was floated on a droplet of the suspension for $5 \mathrm{~min}$ and then lifted upwards and placed on blotting paper to remove any residual water. The sample was then held in a vacuum for $30 \mathrm{~min}$ to completely evaporate the solvent. Moreover, the elemental 
composition of these nanoparticles was analysed by energy dispersive X-ray spectroscopy (EDXS) during TEM and the electron diffraction patterns were utilised to confirm the existence of metallic silver crystalline phases. A PG:Ag sample X-ray irradiated with a dose of 147 Gy was used in this work and was observed by TEM.

\section{Results and discussion}

We previously reported the identification of X-ray-induced silver-, phosphorus- and oxygen-related species produced by X-ray irradiation of a PG:Ag sample [11]. Concerning the radiation-induced Ag-related species, an optical absorption spectrum of the X-ray-irradiated PG:Ag was decomposed into five individual Gaussian bands, marked “A” to “E”, with peaks at 225, 252, 270, 307 and 354 nm, respectively. These bands were, in turn, attributed to $\mathrm{Ag}^{+}, \mathrm{Ag}_{3}{ }^{+}$or $\mathrm{Ag}_{3}{ }^{2+}, \mathrm{Ag}_{2}{ }^{+}, \mathrm{Ag}^{2+}$ and $\mathrm{Ag}^{0}$ centres, respectively, through various optical and thermal measurements [11-13]. Moreover, the excitation spectrum consisted of two different bands. One band had a peak at $308 \mathrm{~nm}$ for an emission at $560 \mathrm{~nm}$ (orange RPL) and the other peaks at 270 and $345 \mathrm{~nm}$ corresponded to a main emission at $470 \mathrm{~nm}$ (blue RPL). The former corresponded to the decomposed $307 \mathrm{~nm}$ Gaussian band, while the latter corresponded to the decomposed 270 and $354 \mathrm{~nm}$ bands, respectively. 
The optical absorption spectrum was obviously due to the superposition of a number of individual optical absorption bands corresponding to different colour centres. To allow better identification of the complicated spectroscopic features in PG:Ag, three-dimensional (3D) contour plots of the PG:Ag as shown in Fig. 1 that was X-ray irradiated with a dose of 12.3 Gy were recorded using the CEES technique [22, 23]. A large number of excitation (or emission) spectra were recorded over a range of emission (or excitation) wavelengths, shifting the emission (or excitation) wavelengths by $3 \mathrm{~nm}$ after every acquisition in a spectral interval extending from $400 \mathrm{~nm}$ to $700 \mathrm{~nm}$ (or from $200 \mathrm{~nm}$ to $400 \mathrm{~nm}$ ), respectively. The resulting 3D data set of emission intensities as functions of the excitation and emission wavelengths is best visualised in a contour plot, where lines of equal emission intensities are drawn as shown in Fig. 1. In the contour plot, both the blue RPL around $470 \mathrm{~nm}$ and the orange RPL around $560 \mathrm{~nm}$ are clearly distinguished and will be discussed later. In addition, the shorter wavelength regions at around $270 \mathrm{~nm}$ in the excitation spectrum that were detected in the region of the blue and orange RPLs were not stable with respect to the peak intensity. This may reflect the characteristics of the induced $\mathrm{Ag}_{2}^{+}\left(\mathrm{Ag}^{+}+\mathrm{Ag}^{0} \rightarrow \mathrm{Ag}_{2}^{+}\right)$centres, i.e., upon changing the $\mathrm{Ag}^{0}$ centre concentration, the $\mathrm{Ag}_{2}{ }^{+}$band with coupling to the $\mathrm{Ag}^{0}$ centres also changed.

Fig. 2(a) shows the optical absorption (Curve 1), excitation (Curve 2) and PL spectra (Curve 3) of 0.3-mm-thick PG:Ag before X-ray irradiation. The $230 \mathrm{~nm}(5.39 \mathrm{eV})$ excitation 
predominantly produced PL at $308 \mathrm{~nm}(4.03 \mathrm{eV})$. Fig. 2(b) shows the optical absorption (Curve 4), excitation (Curves 5 and 6) and RPL spectra (Curves 7, 8 and 9) of the X-ray irradiated PG:Ag with a dose of 12.3 Gy. For the PG:Ag sample, the excitation is in the range of $250-400 \mathrm{~nm}$ and the RPL is in the form of a broad band extending from $400-700 \mathrm{~nm}$. It was found from Figs. 2(a) and (b) that the large number of isolated $\mathrm{Ag}^{+}$ions in the glass before irradiation drastically decreased after irradiation, which suggested that almost all $\mathrm{Ag}^{+}$ions transformed other colour centres to form various silver-related species upon X-ray irradiation and the subsequent reactions. The RPL consist of two different bands. One spectrum peaks at $310 \mathrm{~nm}(4.00 \mathrm{eV})$ for an emission at $560 \mathrm{~nm}(2.21 \mathrm{eV}$, orange RPL), and the other peaks at $270 \mathrm{~nm}(4.59 \mathrm{eV})$ and $345 \mathrm{~nm}(3.59 \mathrm{eV})$ for an emission at $470 \mathrm{~nm}(2.64 \mathrm{eV}$, blue RPL). The optical absorption spectra peaking at $310 \mathrm{~nm}$, which was attributed to $\mathrm{Ag}^{2+}$ centres [10-13]. In the case of the GD-450 dosimeter used in this work, the peak intensity at $310 \mathrm{~nm}$ linearly increased up to 5 Gy for X-ray irradiation [24]. Similar investigations on phosphate- and silicate-based glasses containing silver have been performed by TEM analysis and various optical measurements to understand the origin of the induced bands and the mechanisms of nucleation and growth processes [18, 25-28].

Fig. 3 shows the PL and RPL spectra of X-ray irradiated PG:Ag with a dose of 12.3 Gy during heat treatment at $250^{\circ} \mathrm{C}$ for displayed holding times in minutes. The $308 \mathrm{~nm}(4.03 \mathrm{eV})$ PL and $560 \mathrm{~nm}(2.21 \mathrm{eV})$ RPL emission bands were obtained under excitations at $230 \mathrm{~nm}$ 
(5.39 eV) and $310 \mathrm{~nm}(4.00 \mathrm{eV})$, respectively. The band peaking at $560 \mathrm{~nm}$ ascribed to $\mathrm{Ag}^{2+}$ centres decreased abruptly in intensity with increase in holding time from 10 to 40 minutes, while the band peaking at $308 \mathrm{~nm}$ due to the single $\mathrm{Ag}^{+}$centres increased steadily with holding time. The data indicates that annealing the sample leads to the disappearance of the $270 \mathrm{~nm}$ and $345 \mathrm{~nm}$ excitation bands emitting blue RPL at $470 \mathrm{~nm}$ as shown in Fig. 2(b) by the following reactions, i.e., $\mathrm{Ag}^{0} \rightarrow \mathrm{Ag}^{+}+\mathrm{e}^{-}$(electron) and $\mathrm{Ag}_{2}{ }^{+} \rightarrow \mathrm{Ag}^{0}+\mathrm{Ag}^{+}$, respectively. On the other hand, the $310 \mathrm{~nm}$ excitation band emitting orange RPL at $560 \mathrm{~nm}$ leads to the disappearance by the following reaction, i.e., $\mathrm{Ag}^{2+} \rightarrow \mathrm{Ag}^{+}+\mathrm{h}^{+}$(hole). According to our report [12], it was established through RPL decay curve analysis that the lifetime values for the blue RPL at $470 \mathrm{~nm}$ excited at $270 \mathrm{~nm}$ and $345 \mathrm{~nm}$ in the X-ray irradiated PG:Ag with a dose of 12.3 Gy were obtained 6.38 ns and 5.71 ns, respectively. Moreover, the lifetime values of 345 nm excitation were almost independent of the absorbed doses, while those of $270 \mathrm{~nm}$ excitation were strongly dependent on the doses. These optical results support the evidence on the different origin and structures for the 270 and $345 \mathrm{~nm}$ bands.

Fig. 4 shows the optical absorption spectra after irradiation of X-ray (Curve 1) and fs laser pulses (Curve 2). The optical absorption spectrum is obviously due to the superposition of a number of individual optical absorption bands corresponding to the different colour centres. Therefore, the spectrum could be decomposed into the sum of separate Gaussian bands (indicated by a dashed line) from "A" to "F", respectively. For Curve 2, the peak 
power density of the laser beam irradiated on the sample was estimated to be $1.1 \times 10^{15}$ $\mathrm{W} / \mathrm{cm}^{2}$. Note that irradiation with X-ray and high peak power density fs laser pulses yields different absorption peak wavelengths of the $\mathrm{Ag}^{0}$ centres: the former is $345 \mathrm{~nm}$ ("E" band) and the latter is $407 \mathrm{~nm}(3.05 \mathrm{eV})$ which could be ascribed to the aforementioned SPR of the formed silver nanoparticles $[11,20]$. One of the reasons for this difference is that when fs laser pulses are focused inside the sample at a high repetition rate over $250 \mathrm{kHz}$, the temperature at the focal point increases to as high as several thousand Kelvin [28], a much higher temperature than that reached in normal heat treatment. As a result, highly successive fs laser pulses and a slow scanning rate caused cumulative heating around the focal point. Increasing the temperature greatly increased the average size of nanoparticles formed by fs laser irradiation, resulting in a red-shift of the peak wavelength. It was found from the above results that the $345 \mathrm{~nm}$ band corresponding to the decomposed " $\mathrm{E}$ " band was identifiable as the tapped electron $\mathrm{Ag}^{0}$ centres due to almost overlap between the "E" and SPR band. In addition, the $270 \mathrm{~nm}$ band corresponding to the decomposed "C" band also increases in intensity after high intensity fs laser pulses as shown in Fig. 4, therefore the "C" band was identifiable as the $\mathrm{Ag}_{2}{ }^{+}$centres (reaction: $\mathrm{Ag}^{+}+\mathrm{Ag}^{0} \rightarrow \mathrm{Ag}_{2}{ }^{+}$). As increasing the $\mathrm{Ag}^{0}$ centres, then the $\mathrm{Ag}_{2}{ }^{+}$band with coupling to $\mathrm{Ag}^{0}$ centres also increases.

On the other hand, the $310 \mathrm{~nm}$ band corresponding to the decomposed " $\mathrm{D}$ ” band was attributed to the trapped hole $\mathrm{Ag}^{2+}$ centres (reaction: $\mathrm{Ag}^{+}+\mathrm{h}^{+} \rightarrow \mathrm{Ag}^{2+}$ ). In the case of PG:Ag, 
the holes are captured by $\mathrm{PO}_{4}$ tetrahedron at the beginning of the migration and then the holes come to produce the $\mathrm{Ag}^{2+}$ centres due to interaction with $\mathrm{Ag}^{+}$ion by the time passing [29]. As a result, the $\mathrm{Ag}^{0}$ centres can form and grow quickly under elevated temperatures at the beginning stage after fs laser irradiation, while the $\mathrm{Ag}^{2+}$ centres need long elapsed time to form. A prominent decrease in intensity around " $\mathrm{D}$ ” band may be considered to reflect the above explanation. As described above, no discernible absorption band for the silver nanoparticles due to SPR was observed in this work after heavy X-ray irradiation up to a 147 Gy and further annealing at $573 \mathrm{~K}$ for $30 \mathrm{~min}$.

Preliminary observation by TEM was carried out on a PG:Ag sample as shown in Fig. 5(a) that received a dose of 147 Gy to confirm the size, shape and aggregation of the nanoparticles generated by X-ray irradiation. Fig. 5(b) is the corresponding high-resolution image taken from Fig. 5(a). The diameters of the particles were in the range of 5-10 nm, and larger particles with diameters of up to approximately $30 \mathrm{~nm}$ were also observed. Figs. 5(c) and (d) show the X-ray spectra for "silver poor" and "silver rich" regions, respectively, which were collected at a tube voltage of $8 \mathrm{keV}$ to evaluate the Ag L $\alpha$-line using EDXS. As shown in the figures, aside from the $\mathrm{Ag} \operatorname{L} \alpha(2.984 \mathrm{keV})$-line, the X-ray spectra also contained peaks originating from $\mathrm{P}, \mathrm{O}, \mathrm{Al}$ and $\mathrm{Na}$, which arise from the surrounding glass. The $\mathrm{Cu}$ and $\mathrm{C}$ peaks were due to the $\mathrm{Cu}$-containing grid and the $\mathrm{C}$ support film. 
A lattice fringe spacing of approximately $0.22-0.30 \mathrm{~nm}$ was observed in the precipitated particles as shown in Fig.6 (a), which is in good agreement with those of $0.24 \mathrm{~nm}$ (Ag (1 11 1)) and 0.28-0.3 nm (silver oxide) in soda-lime silicate glasses [25] and silica thin films [26] with Ag particles. A qualitative composition analysis using EDXS during TEM confirmed that these spherical particles were silver nanoparticles. Moreover, in order to determine the crystalline structure of Ag-related species in the X-ray irradiated PG:Ag, the X-ray diffraction (XRD) patterns were measured at room temperature in air as shown in Fig. 6(b). The results exhibited broad humps at $2 \theta=15-40^{\circ}$ and $60-70^{\circ}$, which indicated the sample was amorphous and high concentration of $\mathrm{H}_{3} \mathrm{PO}_{4}$. Due to relatively low concentration of $\mathrm{Ag}(0.17 \mathrm{wt} \%)$ in this work, a series of diffraction peaks corresponded to the $\mathrm{Ag}_{2} \mathrm{O}$ (111), $2 \theta=32.791^{\circ}$; $\mathrm{Ag}(111)$, $2 \theta=38.117^{\circ}$ and $\mathrm{Ag}_{2} \mathrm{O}$ (220), $2 \theta=54.904^{\circ}$ plane diffractions did not appear in the XRD measurements. Therefore, we could not determine the existence ratio between Ag- and $\mathrm{Ag}_{2} \mathrm{O}$-species formed in X-ray irradiated PG: Ag.

\section{Conclusions}

The data obtained in this study yielded the following conclusions:

(1) Though no discernible characteristic silver band around $407 \mathrm{~nm}(3.05 \mathrm{eV})$ due to the SPR could be observed in the optical absorption spectra after X-ray irradiation, even after a dose of 
$147 \mathrm{~Gy}$ and subsequent heat treatment up to $350^{\circ} \mathrm{C}$, the aforementioned fs laser pulse results indicated that the $345 \mathrm{~nm}(3.59 \mathrm{eV})$ band corresponding to the decomposed "E" band ascribed to the $\mathrm{Ag}^{0}$ centres in X-ray irradiated PG:Ag almost overlapped the SPR band of the formed silver nanoparticles. As a result, the presence of silver atoms and silver oxide particles embedded in the PG:Ag was confirmed through information provided by the lattice fringe spacings and EDXS analysis during TEM.

(2) Preliminary direct observation by TEM showed spherical particles with diameters ranging from 5 to $10 \mathrm{~nm}$, along with larger particles with diameters of up to approximately $30 \mathrm{~nm}$ in the phosphate glass sample. However, we could not determine from the present measurements the existence ratio between $\mathrm{Ag}$ - and $\mathrm{Ag}_{2} \mathrm{O}$-species formed by $\mathrm{X}$-ray irradiation.

(3) The spectroscopic features of various colour centres in PG:Ag formed after X-ray irradiation were clearly identified and visualised using a contour plot obtained using the CEES technique.

\section{Acknowledgements}

We would like to thank Ms. Y. Miyamoto and Mr. K. Ohno for their contributions to the CEES measurements at Kanazawa Institute of Technology (KIT) and Prof. H. Nanto at KIT for his fruitful discussions. We would also like to thank Prof. C. Watanabe and Dr. A. Taoka at Kanazawa University for their contributions to the TEM experiments. 


\section{Figure captions}

\section{Fig. 1}

Contour plot of CEES measurement of X-ray-irradiated PG:Ag with a dose of $12.3 \mathrm{~Gy}$ at room temperature.

Fig. 2

Optical absorption (Curve 1), excitation (Curve 2) and photoluminescence (Curve 3) spectra before irradiation (a) and optical absorption (Curve 4), excitation (Curves 5 and 6) and RPL (Curves 7, 8 and 9) spectra after X-ray irradiation (b) of Ag-doped phosphate glass.

Fig. 3

Photoluminescence excited at $230 \mathrm{~nm}$ (a) and RPL excited at $310 \mathrm{~nm}$ (b) emission spectra of X-ray irradiated Ag-doped phosphate glass during heat treatment at $250{ }^{\circ} \mathrm{C}$ for displayed holding times in minutes. For a reference, PL spectrum before irradiation was inserted.

Fig. 4

Absorption spectra of Ag-doped phosphate glass after X-ray (Curve 1) irradiation with a dose of 12. 3Gy and after fs laser pulse (Curve 2) irradiation with a peak power $1.1 \times 10^{15}$ $\mathrm{W} / \mathrm{cm}^{2}$. For Curve 1 , the absorption spectrum was decomposed into six bands from "A" to "F". 
Fig. 5

TEM images of Ag nanoparticles embedded in the phosphate glass (a, b), (b) shows the high-magnification imaging after X-ray irradiation with an absorbed dose of 147 Gy. The EDXS analysis was carried out the areas with (c) and without (d) nanoparticles.

\section{Fig. 6}

TEM image of a lattice fringe spacing (a) of nanoparticles and XRD pattern (b) of X-ray irradiated Ag-doped phosphate glass. 


\section{References}

[1] M. Ranogajec-Komor, Ž. Knežević, S. Miljanić, B. Vekić, Radiat. Meas. 43 (2-6) (2008) 392-396.

[2] J. H. Lee, M. S. Lin, S. M. Hsu, I. J. Chen, W. L. Chen, C. F. Wang, Radiat. Meas. 44 (1) (2009) 86-91.

[3] Chiyoda Technol Corporation, http://www.c-technol.co.jp/technol_eng/ (2007).

[4] Ž. Knežević, N. Beck, D. Milković, S. Miljanić, M. Ranogajec-Komor, Radiat. Meas. (2011) doi: 10.1016/j.radmeas.2011.05.042.

[5] P. Olko, Radiat. Meas. 45 (3-6) (2010) 506-511.

[6] M. Ranogajec-Komor, NATO Science for Peace and Security Series B: Physics and Biophysics, Ed. G. A. Aycik, Springer, Dordrecht (2009) 97-112.

[7] R. Yokota, H. Imagawa, J. Phys. Soc. Jpn. 23 (5) (1966) 1038-1048.

[8] H. Hosono, Y. Abe, H. Kawazoe, J. Non-Cryst. Solids 71 (1-3) (1985) 261-267.

[9] P. Ebeling, D. Ehrt, M. Friedrich, Opt. Mater. 20 (2) (2002) 101-111.

[10] T. Kurobori, W. Zheng, Y. Miyamoto, H. Nanto, T. Yamamoto, Opt. Mater. 32 (9) (2010) 1231-1236.

[11] W. Zheng, T. Kurobori, Y. Miyamoto, H. Nanto, T. Yamamoto, Radiat. Meas. (2011) doi:10.1016 /j.radmeas.2011.01.004.

[12] W. Zheng, T. Kurobori, J. Lumin. 131 (1) (2011) 36-40.

[13] T. Kurobori, W. Zheng, C. Zhao, IOP Conf. Series: Mater. Sci. Eng. 15(1) (2010) 012026-012033.

[14] X. C. Yang, Z. W. Dong, H. X. Liu, J. X. Xu, S. X. Qian, Chem. Phys. Lett. 475 (4-6) (2009) 256-259.

[15] Y. Takeda, O. A. Plaksin, N. Kishimoto, Opt. Express 15(10) (2007) 6010-6018.

[16] K. Bourhis, A. Royon, M. Bellec, J. Choi, A. Fargues, M. Treguer, J. J. Videau, D. Talaga, M. Richardson, T. Cardinal, L. Canioni, J. Non-Cryst. Solids 356 (44-49) (2010) 2658-2665.

[17] C. Maurel, T. Cardinal, M. Bellec, L. Canioni, B. Bousquet, M. Treguer, J. J. Videau, J. Choi, M. Richardson, J. Lumin. 129 (12) (2009) 1514-1518.

[18] Q. Zhao, J. Qiu, X. Jiang, C. Zhao, C. Zhu, Opt. Express 12(17) (2004) 4035-4040.

[19] H. Zeng, J. Qiu, S. Yuan, Y. Yang, G. Chen, Ceram. Int. 34 (3) (2008) 605-608.

[20] J. A. Jiménez, M. Sendova, H. Liu, J. Lumin. 131 (3) (2011) 535-538.

[21] N. H. Ma, H. L. Ma, M. J. Zhong, J. Y. Yang, Y. Dai, G. Ye, Z. Y. Yue, G. H. Ma, J. R. Qiu, Mater. Lett. 63 (1) (2009) 151-153.

[22] V. Dierolf, A. B. Kutsenko, C. Sandmann, Th. Tröser, G. Corradi, J. Lumin. 87-89 (2000) 989-991.

[23] T. Marolo, G. Baldacchini, V. S. Kalinov, R. M. Montereali, phys. stat. sol. (c), 2 (1) (2005) 367-370. 
[24] Y. Miyamoto, K. Kinoshita, H. Kobayashi, A. Fujiwara, S. Koyama, Y. Takei, H. Nanto, T. Yamamoto, T. Kurobori, T. Yanagida, A. Yoshikawa, M. Sakakura, Y. Shimotsuma, K. Miura, K. Hirao, Sensors and Mater. 22 (5) (2010) 235-245.

[25] D. Mangaiyarkarsai, K. Kamada, N. Saito, S. Ichikawa. T. Arai, K. Kadono, T. Yazawa, J. Non-Cryst. Solids 351 (37-39) (2005) 3156-3159.

[26] S. Pal, G. De, Mater. Res. Bull. 44 (2) (2009) 355-359.

[27] J. A. Jiménez, H. Liu, E. Fachini, Mater. Lett. 64 (19) (2010) 2046-2048.

[28] Y. Shimotsuma, K. Hirao, P. G. Kazansky, J. Qiu, Jpn. J. Appl. Phys. 44 (7A) (2005) 4735-4748.

[29] R. Yokota, Ouyo Butsuri 38 (11) (1969) 1077-1083 (in Japanese). 

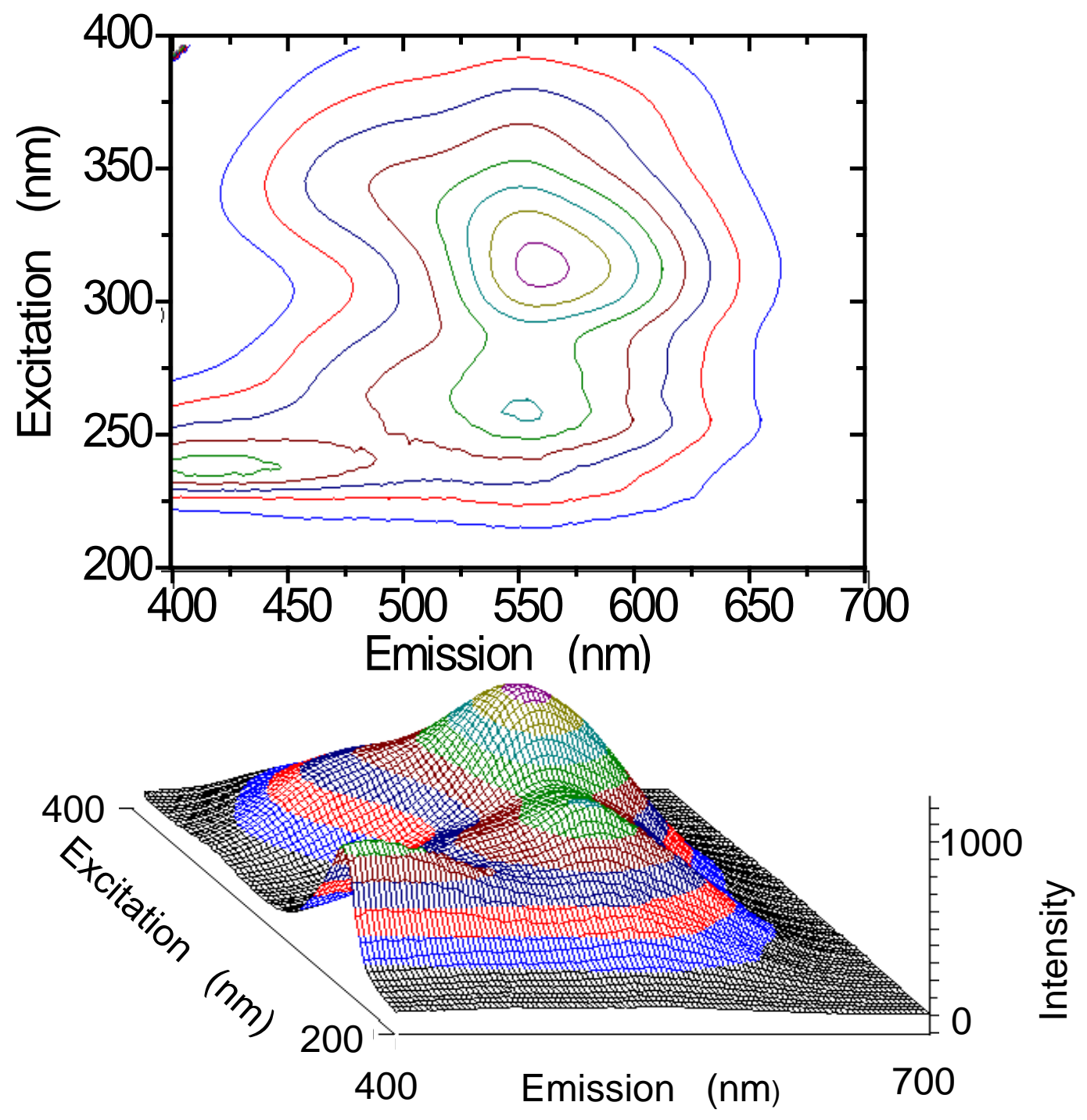

Fig. 1 T. Kurobori 


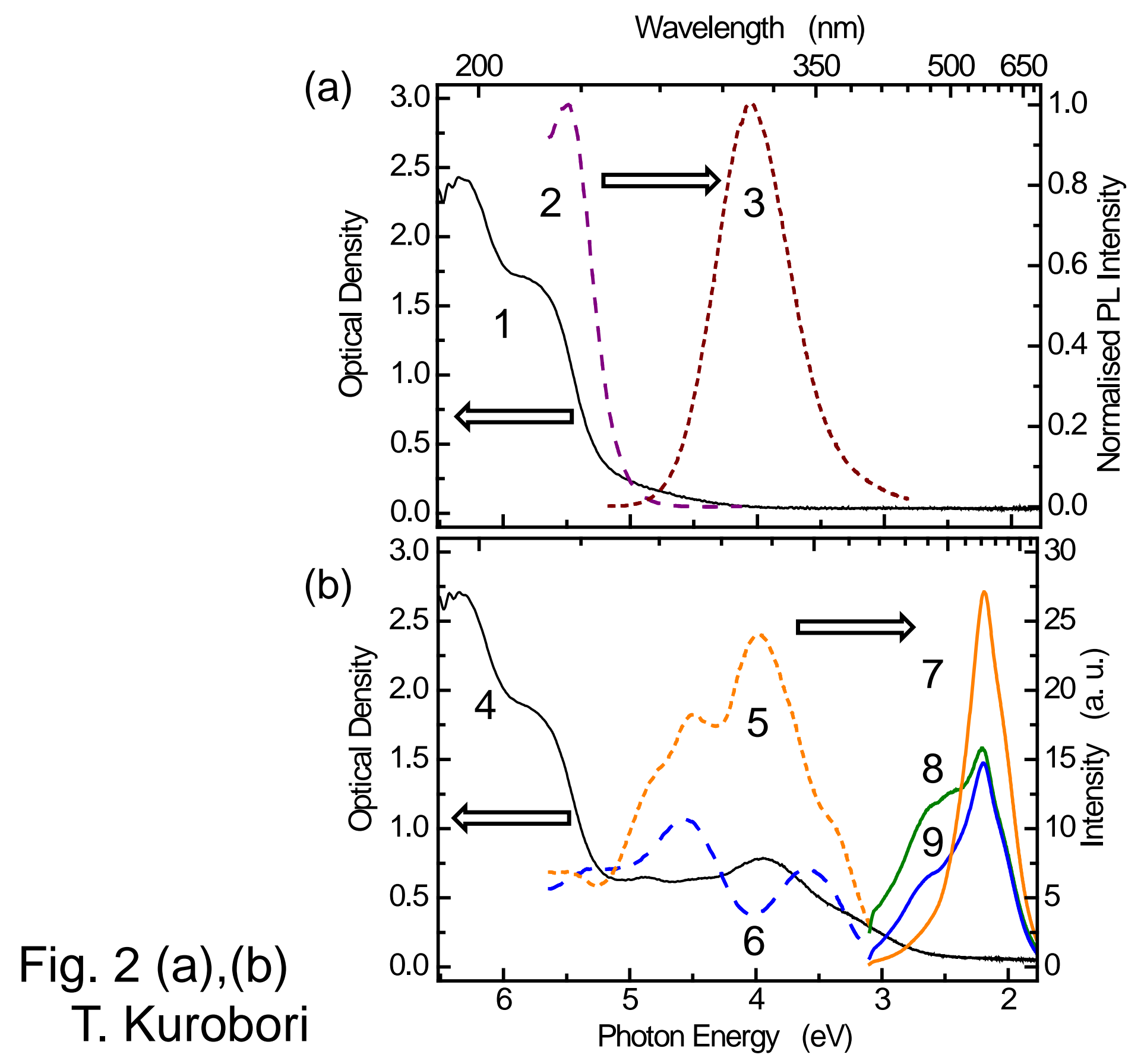




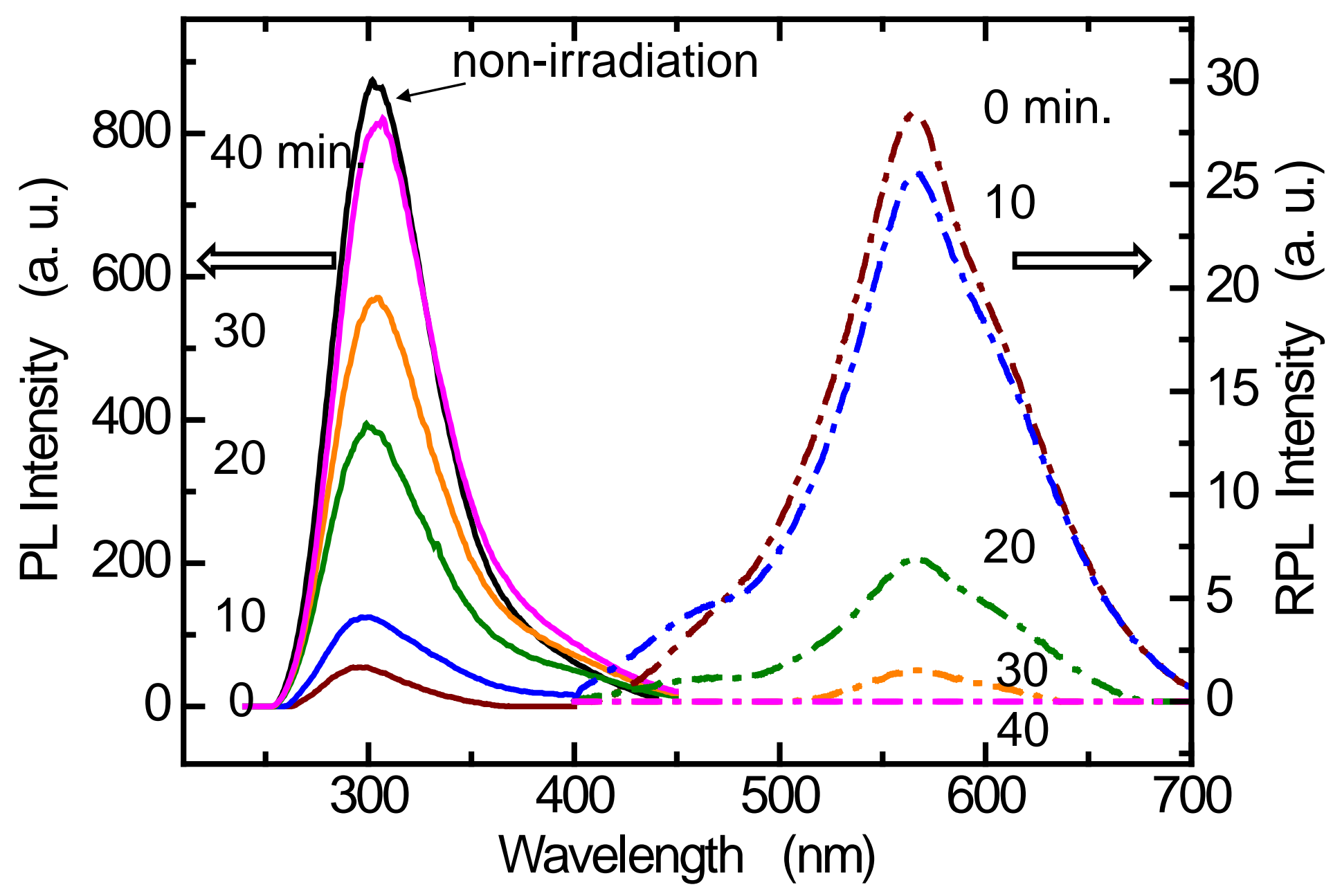

Fig. 3 T. Kurobori 


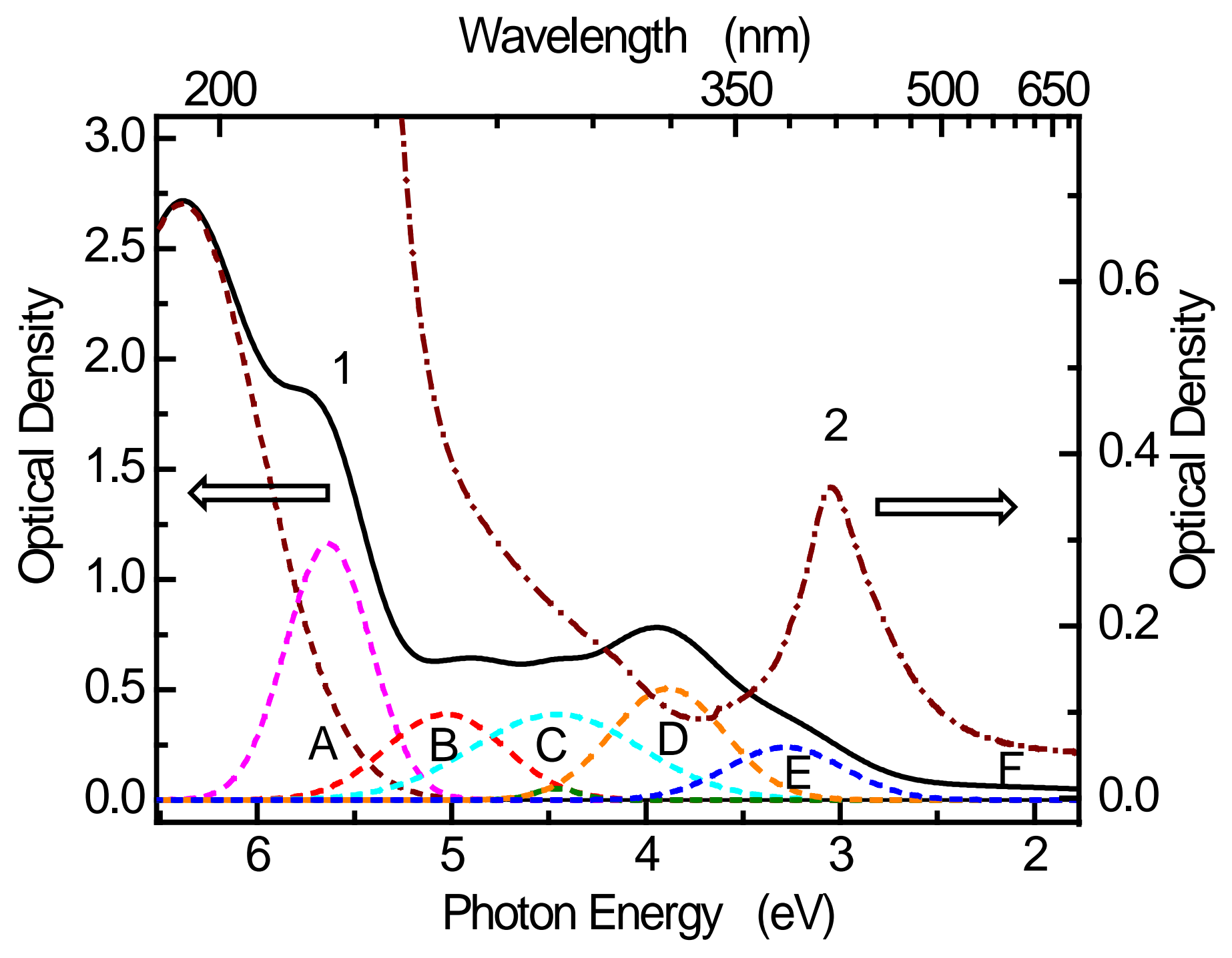

Fig. 4 T. Kurobori 


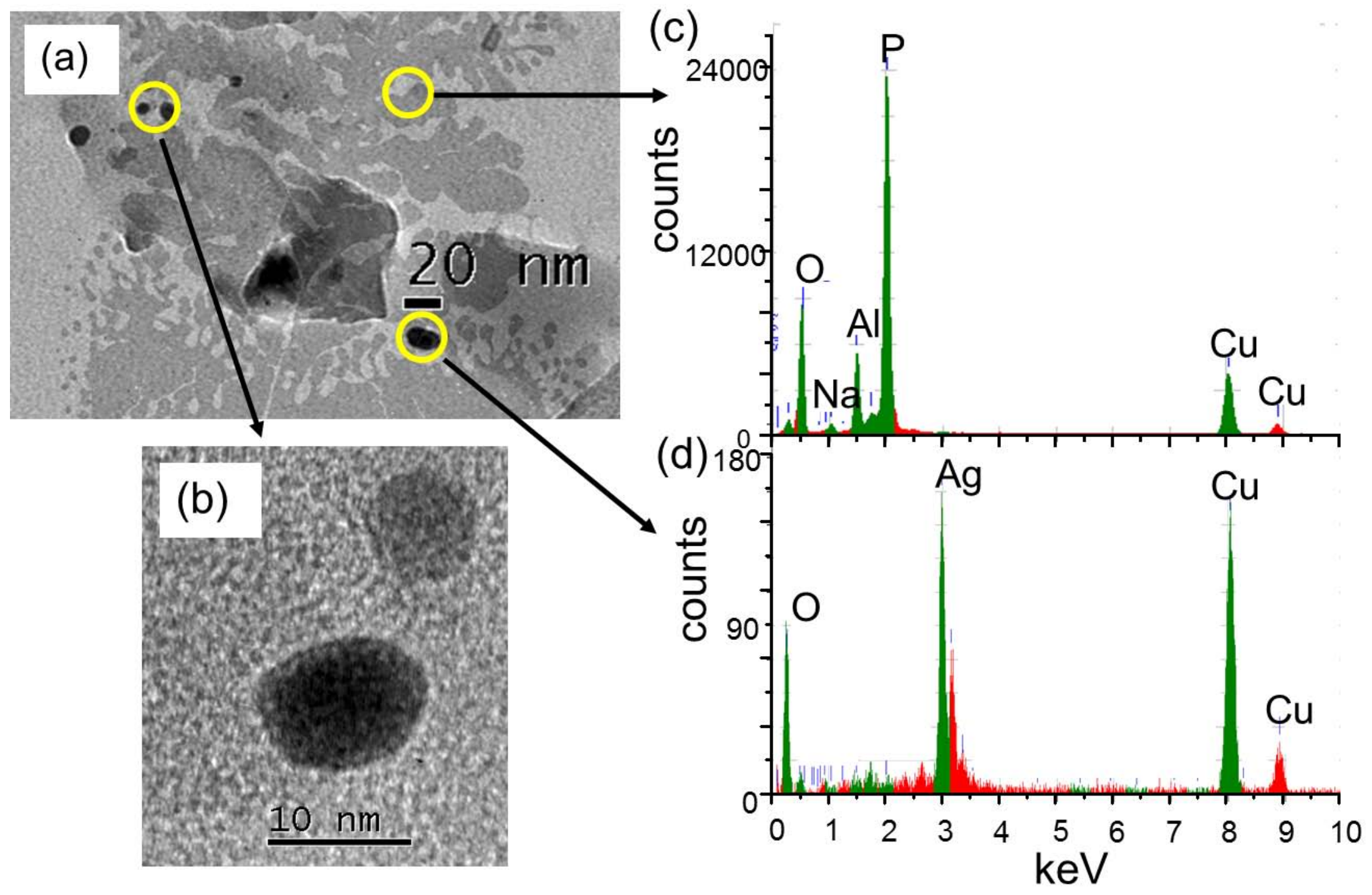

Fig. 5 T. Kurobori 


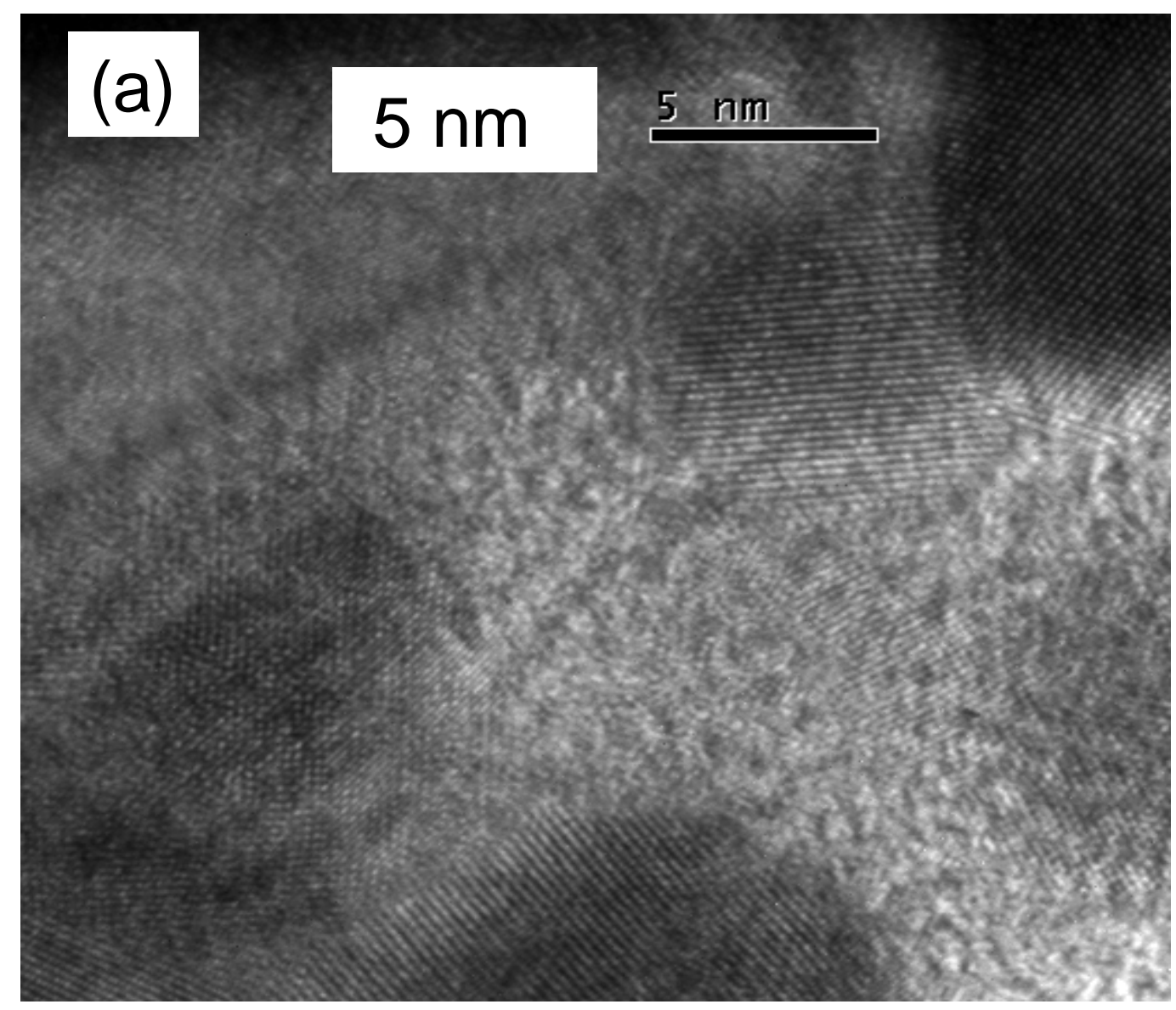

Fig. 6(a) T. Kurobori 
(b)

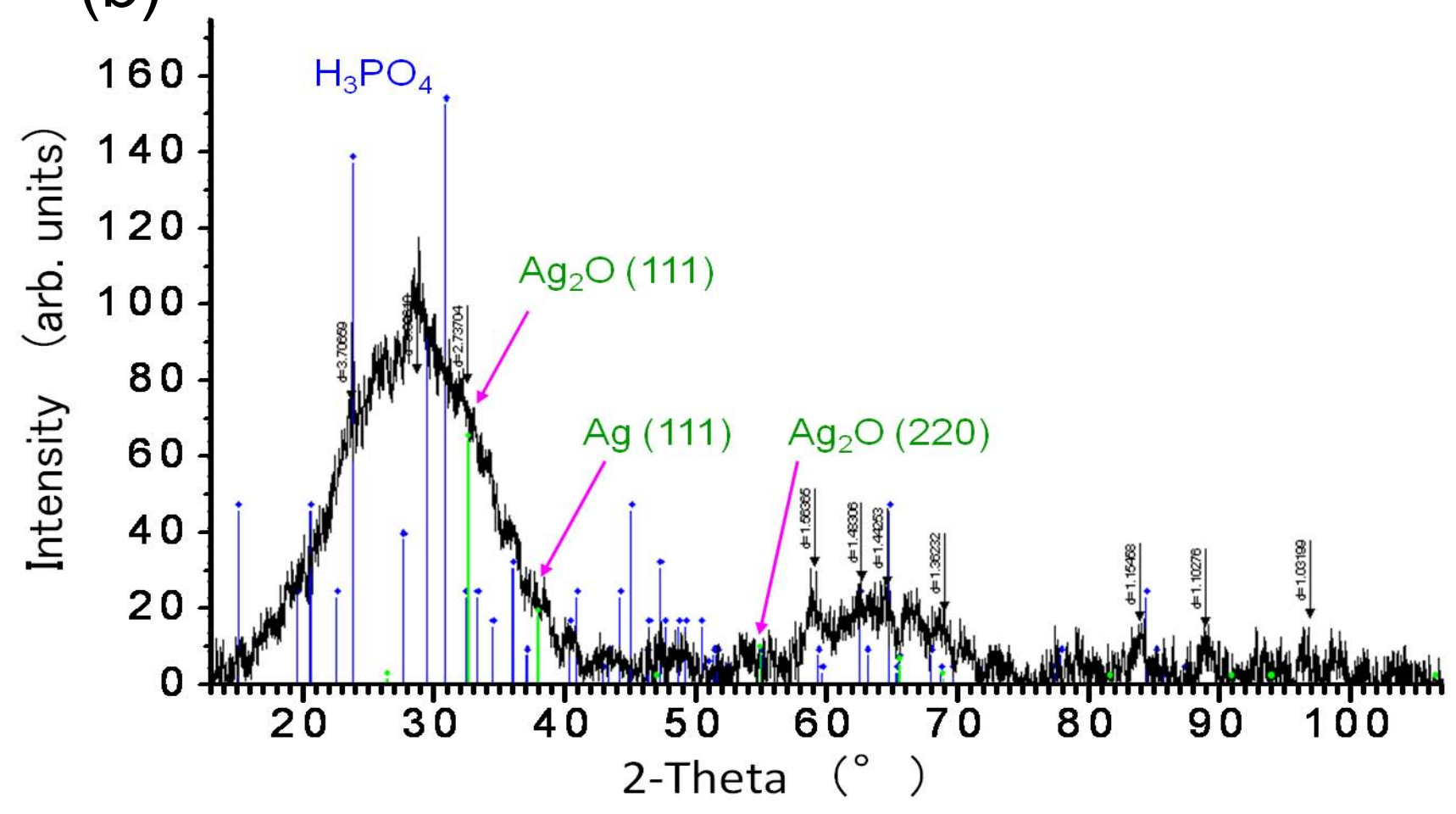

Fig. 6(b) T. Kurobori 